\title{
COVID-19 em profissionais da saúde, vivências e perspectivas: um relato de experiência
}

\author{
COVID-19 in health professionals, experiences and perspectives: an experience report \\ COVID-19 en Profesionales de salud, experiencias y perspectivas: un informe de \\ experiencia
}

Adilson Mendes de Figueiredo Júnior ${ }^{1 *}$, Edilson Ferreira Calandrine ${ }^{1}$, Yasmin Martins de Sousa ${ }^{1}$, Mayara Melo Galvão', Fernanda Furtado da Cunha ${ }^{1}$, Amanda Souza França Veras ${ }^{2}$, Wesllana de Oliveira Ferreira Gonçalves ${ }^{3}$, Deisiane da Silva Mesquita ${ }^{4}$, João Victor Tavares da Costa ${ }^{5}$, Carlos Kayque Araújo da Silva 5 .

\section{RESUMO}

Objetivo: Esse artigo buscou relatar a experiência de profissionais da área da saúde que trabalhavam em um hospital público no combate ao COVID-19 através de um estudo descritivo, tipo relato de experiência, elaborado no contexto de estágio curricular obrigatório da disciplina de Doenças Infecciosas, durante o curso de Graduação em Enfermagem, Fisioterapia e Medicina de uma Universidade pública do estado do Pará. Relato de experiência: Percebeu-se durante o surgimento dos primeiros casos de Coronavírus em Belém-PA que muitos ambientes de trabalho na área assistencial não estavam preparados para o enfrentamento da nova pandemia, principalmente, na preparação psicológica dos profissionais de saúde, pois detectou-se entre enfermeiros, fisioterapeutas e médicos, o medo e a ansiedade que se mostravam presentes em todos os setores hospitalares. Considerações finais: Fica explícito que a nova pandemia modificou o cotidiano assistencial no Brasil, no estado do Pará foi possível observar que muito profissionais não foram assistidos ao ponto de explicitarem seus medos e ansiedades, ou seja, uma grande parcela desses profissionais foi exposta a diversos riscos ocupacionais, principalmente, ao estresse ocupacional, tal risco modificou a rotina de trabalho e até o relacionamento interpessoal fora dos hospitais.

Palavras-chave: Infecções por coronavírus, Educação continuada, Ambiente de trabalho.

\section{ABSTRACT}

Objective: This article sought to report the experience of health professionals who worked in a public hospital in the fight against COVID-19 through a descriptive study, type of experience report, elaborated in the context of mandatory curricular internship in the discipline of Infectious Diseases, during the Undergraduate Nursing, Physiotherapy and Medicine course at a public university in the state of Pará. Experience report: It was noticed during the emergence of the first cases of Coronavirus in Belém-PA that many work environments in the care area were not prepared to face the new pandemic, mainly in the psychological preparation of health professionals, as it was detected among nurses, physiotherapists and doctors, the fear and anxiety that were present in all hospital sectors. Final considerations: It is clear that the new pandemic changed the daily care in Brazil, in the state of Pará it was possible to observe that many professionals were not assisted to the point of explaining their fears and anxieties, that is, a large portion of these professionals were exposed to several occupational risks, mainly to occupational stress, this risk changed the work routine and even the interpersonal relationship outside hospitals.

Key words: Coronavirus infections, Continuing education, Work environment.

1 Universidade do Estado do Pará (UEPA), Belém - PA. *E-mail: adilsonmdfj@hotmail.com

2 Escola Superior da Amazônia (ESAMAZ), Belém - PA.

${ }^{3}$ Universidade Federal do Pará (UFPA), Belém - PA.

${ }^{4}$ Instituto Evandro Chagas (IEC), Belém - PA.

${ }^{5}$ Centro Universitário FAMAZ (UNIFAMAZ), Belém - PA. 


\section{RESUMEN}

Objetivo: Este artículo buscó relatar la experiencia de los profesionales de la salud que laboraron en un hospital público en la lucha contra el COVID-19 a través de un estudio descriptivo, tipo de relato de experiencia, elaborado en el contexto de la pasantía curricular obligatoria en la disciplina de Enfermedades Infecciosas, durante la Curso de Licenciatura en Enfermería, Fisioterapia y Medicina en una universidad pública del estado de Pará. Informe de experiencia: Durante el surgimiento de los primeros casos de Coronavirus en Belém-PA, muchos ambientes laborales en el área de atención no estaban preparados para enfrentar la nueva pandemia. Principalmente en la preparación psicológica de los profesionales de la salud, ya que se detectó entre enfermeras, fisioterapeutas y médicos, el miedo y la ansiedad que estaban presentes en todos los sectores hospitalarios. Consideraciones finales: Es claro que la nueva pandemia cambió la atención diaria en Brasil, en el estado de Pará, se pudo observar que muchos profesionales no fueron atendidos hasta el punto de explicar sus miedos y ansiedades, es decir, una gran parte de estos profesionales estuvieron expuestos a diversos riesgos laborales, principalmente, ante el estrés laboral, este riesgo cambió la rutina laboral e incluso la relación interpersonal fuera de los hospitales.

Palabras clave: Infecciones por coronavirus, Educación continua, Ambiente laboral.

\section{INTRODUÇÃO}

Em meados de dezembro de 2019 o mundo tomou conhecimento de uma nova doença respiratória que se acredita ter surgido no mercado de Wuhan na China. Tal doença ficou conhecida como Coronavírus Disease 2019 (COVID-19) e atingiu milhões de pessoas em diversos países em todo planeta, a COVID-19 mostrou-se como uma doença de alta transcendência e fez o planeta rever seus protocolos assistenciais e de biossegurança, caracterizada como uma pandemia, a mesma apresentou taxas elevadas de incidência em todos os continentes e, dessa forma, transformou o cotidiano de milhões de pessoas (SIMPSON N, et al., 2020).

Com manifestações sistêmicas, a COVID-19 ficou caracterizada primeiramente por sintomas respiratórios, visto a predileção do vírus pelas células pulmonares. Mas, com a investigação epidemiológica e clínica da doença foi possível identificar sinais e sintomas similares a outras viroses, como: mialgia, hipertermia, fadiga e falta de apetite. Inicialmente, acreditava-se que populações no extremo das idades (idosos e crianças) eram mais susceptíveis a infecção, mas constatou-se que o grupo de risco para a doença era formado por indivíduos com doenças respiratórias prévias, portadores de diabetes e hipertensão e portadores de doenças que diminuíssem a resposta imunológica do corpo (KORBER B, et al., 2020).

A contaminação da doença foi definida como sendo por via respiratória, e pela facilidade de transmissão, milhões de pessoas se contaminaram no planeta, sendo que alguns indivíduos apresentaram quadros assintomáticos da doença, enquanto outros manifestavam sintomas característicos mais leves e outros mais graves.

Por se tratar de um número tão alto de infectados, os serviços de saúde enfrentaram o desgaste de suas estruturas e a sobrecarga de seus profissionais de saúde envolvidos, muitos doentes não tiveram, infelizmente, a oportunidade de serem atendidos nos serviços de referência, e assim, mantinham-se sem tratamento e transmitindo o vírus para o meio ambiente (FAUVER JR, et al., 2020).

Atualmente, não existem medicamentos $100 \%$ eficazes e nem vacinas disponíveis para o tratamento da doença, e muitas ainda são as especulações sobre a imunidade adquirida pós-infecção. Dessa forma, o isolamento social e os cuidados de suporte em saúde ainda se mostram como formas preventivas essenciais para evitar a disseminação do vírus. Por não haver um tratamento específico para a COVID-19, muitos profissionais da saúde exercem, incansavelmente, suas atribuições com a finalidade de ofertar um tratamento eficaz e respeitoso aos seus pacientes (SHARMA SK, et al., 2020).

Com o surgimento da pandemia foi possível observar que o mundo não estava preparado para lidar com a grandiosidade e especificidade da doença, assim, questões de planejamento, preparação das equipes de saúde, organização de políticas públicas e, principalmente, aspectos de proteção dos profissionais 
envolvidos se mostravam ineficientes nesse momento. Com a representatividade desses problemas, muitos profissionais da saúde ficavam expostos ao risco de infecção e começaram a apresentar crises de ansiedade e transtorno do pânico (MERMIKIDES A, 2020; HOU YJ, et al., 2020).

Além das questões envolvendo a saúde, a pandemia mostrou outras faces que envolveram questões políticas e até critérios econômicos de vários líderes pelo mundo, com essa nova dinâmica observou-se o surgimento de diversas teorias sobre a doença e Fake News (notícias falsas) que permitiram com que sentimentos como a angústia se tornassem presentes entre a população em geral e mais especificamente entre os profissionais da saúde. O trabalho contínuo e de qualidade dos diversos profissionais da saúde expuseram os mesmos a inúmeros cenários de atuação e mesmo com todo o reconhecimento profissional, muitos não tiveram apoio psicológico e até mesmo biológico em seus ambientes laborais (TURALE S, et al., 2020).

As diversas características biológicas, sociais, políticas e mentais que a doença proporcionou no cenário mundial não poderiam ser previstas no início do ano de 2020, assim muitos profissionais envolvidos com o cuidado se infectaram e alguns evoluíram ao óbito.

A perda de pacientes e dos próprios companheiros de trabalho exigia cada vez mais determinação, coragem e destreza por parte dos médicos, fisioterapeutas, enfermeiros e outros profissionais da saúde. Mas, com a fragilidade da situação e pressão nos ambientes de trabalho, a exaustão e o medo se fizeram mais presentes e influenciaram negativamente o exercício laboral de milhares de pessoas (CATTON RNH, 2020). Esse artigo buscou relatar a experiência de profissionais da área da saúde que trabalhavam em um hospital público no combate ao COVID-19 através de um estudo descritivo, tipo relato de experiência.

\section{RELATO DE EXPERIÊNCIA}

Foi realizado no período de 01 de abril até 03 de abril de 2020, em um hospital público referência no tratamento de doenças infecto-parasitárias localizado na cidade de Belém-PA. O hospital foi referência no tratamento de portadores do vírus do COVID-19 e ofertou internações ambulatoriais e em Unidades de Tratamento Intensivo (UTI).

Utilizamos como metodologia a observação da rotina da assistência da equipe multiprofissional e quanto aos relatos das atividades cotidianas foram realizadas através de conversas informais com os profissionais presentes no hospital que eram caracterizados em um quantitativo de 02 médicos, 02 enfermeiros e 02 fisioterapeutas. Durante a rotina, os profissionais envolvidos manifestavam seus relatos logo após o contato com os pacientes e percebiam-se os diversos sentimentos envolvidos durante a abordagem (medo, ansiedade e preocupação), muitos desses sentimentos eram confirmados posteriormente pelos abordados.

Dos 06 profissionais envolvidos, 03 trabalhavam na UTI (01 médico, 01 enfermeiro e 01 fisioterapeuta), com faixa etária entre 30 e 39 anos e todos com mais de 05 anos de experiência profissional no hospital. Mesmo com o tempo circunstancial de exercício profissional no hospital, esses profissionais relataram que a nova pandemia era diferente de qualquer outra doença já enfrentada pelos em suas vidas profissionais, pois de acordo com seus relatos, percebiam que os sistemas públicos e privados de saúde não estavam preparados para a grandiosidade dos aspectos biológicos, sociais e mentais da doença.

Todos os profissionais ouvidos, independente de suas áreas de atuação no hospital, relataram que o medo era o sentimento mais presente e o mais preocupante durante o exercício profissional, principalmente, pela possibilidade de transmissão do vírus para familiares mais próximos. Tal situação fez com que esses profissionais se isolassem em hotéis e no próprio hospital para reduzir as possibilidades de transmissão. Com o isolamento, a preocupação com a família, com os pacientes e com próprio bem-estar se fazia mais intensa e contínua.

Os profissionais envolvidos relataram que o dimensionamento de informações sobre a doença e o número de óbitos no Brasil gerava uma sensação de fragilidade e, muitas vezes, causavam reações psicossomáticas que se assimilavam com os sinais e sintomas da COVID-19, tal fato, gerou crises de ansiedade que, por vezes, interferiram diretamente na prática do cuidado aos pacientes. Alguns dos 
profissionais que participaram do relato, afirmaram que evitavam em alguns casos um contato muito próximo e/ou duradouro com os doentes, mesmo com a utilização de Equipamento de Proteção Individual (EPI).

Todos os profissionais ouvidos afirmaram que a pandemia mudou completamente a forma de trabalhar e que os efeitos da pandemia ainda irão se estender por alguns meses, inclusive, na qualidade e efetividade da assistência em saúde pelos profissionais envolvidos. É necessário, de acordo com o relato dos informantes, maiores investimentos nas formas de valorização trabalhista, principalmente, dentro de uma abordagem com o real conceito de saúde, ou seja, com ações direcionadas para o equilíbrio biológico, social e mental.

\section{DISCUSSÃO}

O potencial do vírus da COVID-19 não afetou apenas a estrutura de saúde assistencial no mundo, mas influenciou diretamente na qualidade de vida e no potencial assistencial dos profissionais envolvidos. Mesmo com ajudas externas, como doações financeiras, de insumos da saúde e apoio político, muitas vezes, o profissional envolvido no cuidado enfrentou diversas dificuldades no âmbito de suas necessidades mentais e sociais, dessa forma, percebeu-se que a doença tomou proporções muito além de um simples conceito de patologia (ARONS MM, et al., 2020).

De acordo com os estudos que envolveram a COVID-19 muitas instalações de saúde ainda apresentava estruturas de vulnerabilidade e fragilidade tal fato aumentou a proporção de profissionais de saúde adoecidos sendo que muitos se tornaram a sintomáticos mas mesmo assim continuaram a contaminar outros colegas de trabalho famílias tal característica também foi um dos elementos de maior pressão psicológica sobre esses profissionais pois muitos se sentir um responsáveis pela propagação da doença principalmente em seu meio de convívio social (MCMICHAEL TM, et al., 2020).

Os profissionais da saúde sempre desempenharam um papel importante na prevenção e no controle de doenças infectocontagiosas e/ou crônico-degenerativas, assim observa-se um papel fundamental na concretização e fortalecimento da saúde pública e, dessa forma, pode-se afirmar que os profissionais de saúde representavam a linha de frente ao combate do COVID-19 e por se tratar de profissionais que exigiram tanto de si, muitos acabaram com "cicatrizes", muitas vezes, irreversíveis ou até mesmo marcados pelo óbito (MO Y, et al., 2020).

Com a velocidade do crescimento da COVID-19 e de suas formas de transmissão, muitos hospitais e clínicas se mostravam despreparados para enfrentá-la corretamente, sendo que seus recursos financeiros e profissionais não acompanharam a mesma velocidade e muitos profissionais se expuseram de maneira perigosa em seus ambientes de trabalho. Nessas situações, tais profissionais, refletiam constantemente sobre os riscos ali presentes e relatavam uma determinada impotência frente às possibilidades de contaminação no ambiente hospitalar, assim infelizmente, muitos evoluíram para casos graves de ansiedade e até mesmo depressão (ARONS MM, et al., 2020).

Mesmo após 6 meses do surgimento da COVID-19 e de sua conceituação como pandemia, as áreas de exposição e os riscos ocupacionais dos profissionais de saúde continuam presentes e, mundialmente, crescem os números de afastamento dos ambientes de trabalho por motivos relacionados à pressão na assistência prestada. Percebe-se que muitos profissionais tiveram que lidar com suas perdas no meio de trabalho, de amigos e familiares, isso agregou à pandemia características de comoção em todos os setores produtivos (MO Y, et al., 2020).

É um grande desafio preparar as instituições de saúde para uma abordagem holística de seus trabalhadores, principalmente, em um cenário de pandemia. Foi possível identificar em diversos países, diferentes formas de representação da doença nos profissionais da saúde, ou seja, as preocupações, medos e ansiedades geraram reflexos variados entre os profissionais da saúde, como: perda de cabelo, anorexia, reações psicossomáticas graves, transtorno de ansiedade, impotência sexual e problemas de relação interpessoal (NIE Q, et al., 2020). 
Muitos foram os profissionais recrutados para o combate à pandemia, principalmente, para Unidades de Tratamento Intensivo (UTI) e, uma grande maioria, foi selecionada sem formação e treinamento no atendimento de pacientes críticos, tal situação, agravou ainda mais a exposição ocupacional e, dessa forma, foi possível perceber o afastamento em quase $40 \%$ de todas as classes de profissionais da saúde que trabalhavam no combate à COVID-19 em UTIs, independentemente de suas áreas específicas e do tempo de formados (RAURELL-TORREDÀ M, et al., 2020).

O esgotamento físico e psicológico durante a pandemia facilitou o afastamento do corpo de saúde dos hospitais em todo o mundo, sendo que $4 \mathrm{em}$ cada 10 profissionais precisaram de acompanhamento psicológico para retornarem aos seus postos de trabalho. Infelizmente, além dos afastamentos profissionais, o óbito se fez presente em 2 em cada 10 profissionais, entre as diversas especialidades que estavam envolvidos com o enfrentamento da COVID-19 (MO Y, et al., 2020; NIE Q, et al., 2020, ARONS MM, et al., 2020).

Os profissionais de saúde estão em alto risco de estarem infectados porque estão mais próximos aos pacientes. A pandemia de COVID-19 é estressante para profissionais de saúde. Estudos mostram que profissionais de saúde sofrem de sofrimento psicológico devido à pandemia de COVID-19. Eles experimentam considerável sofrimento psicológico ao trabalhar com pacientes com diagnóstico de COVID19 , incluindo social isolamento, conflitos de papéis, medo e ansiedade e, dessa forma, a COVID-19 continua transformando o cenário mundial (ZHANG Y, et al., 2020).

Percebe-se que a pandemia da COVID-19 transformou a organização social mundial e, principalmente, modificou os ambientes de trabalho, como os serviços de saúde. Foi observada uma grande pressão no desenvolvimento das atividades assistenciais dos profissionais da saúde envolvidos, com a mudança de protocolos, informações e condutas hospitalares, muitos profissionais enfrentaram inúmeras dificuldades para gerenciar sua força produtiva e, dessa forma, exerceram suas funções muitas vezes de forma contínua e cansativa. Tal fato refletiu diretamente na qualidade da vida desses profissionais e muitos passaram a manifestar episódios de ansiedade, medo e frustração. Assim, espera-se que com a reflexão apresentada, os centros de assistência aos portadores da COVID-19 possam aprimorar protocolos que visem à saúde do trabalhador e a valorização de suas características subjetivas.

\section{REFERÊNCIAS}

1. ARONS MM, et al. Presymptomatic SARS-CoV-2 Infections and Transmission in a Skilled Nursing Facility. The New England Journal of Medicine, 2020; 382(22): 2081-2090.

2. CATTON RNH. Nursing in the COVID-19 pandemic and beyond: protecting, saving, supporting and honouring nurses. International Nursing Review, 2020; 1(1): 157-159.

3. FAUVER JR, et al. Coast-to-Coast Spread of SARS-CoV-2 during the Early Epidemic in the United States. Cell, 2020; (1)181: 990-996.

4. HOU YJ, et al. SARS-CoV-2 Reverse Genetics Reveals a Variable Infection Gradient in the Respiratory Tract. Cell, 2020; (1)182: 429-446.

5. KORBER B, et al. Tracking Changes in SARS-CoV-2 Spike: Evidence that D614G Increases Infectivity of the COVID19 Virus. Cell, 2020; (1)182: 812-827.

6. MCMICHAEL TM, et al. Epidemiology of Covid-19 in a Long-Term Care Facility in King County, Washington. The New England Journal of Medicine, 2020; 21(1): 2005-2011.

7. MERMIKIDES A. Drama out of a crisis: the cultural sector responds to healthcare professional impacted by COVID19. Nature Immunology, 2020; 21(1): 817-818.

8. MO Y, et al. Work stress among Chinese nurses to support Wuhan in fighting against COVID-19 epidemic. J Nurs Manag., 2020; 28(1): 1002-1009.

9. NIE Q, et al. Nursing Management of Severe COVID-19 Patients Undergoing Extracorporeal Membrane Oxygenation Combined with Prone Position Ventilation. Forum Multimedia Publishing, 2020; 23(4): 422-425.

10. RAURELL-TORREDÀ M, et al. Reflexiones derivadas de la pandemia COVID-19. Sociedad Espa nola de Enfermer' Ia Intensiva y Unidades Coronarias (SEEIUC), 2020; 31(2): 90-93.

11. SHARMA SK, et al. Clinical nursing care guidance for management of patient with COVID-19. J Pak Med Assoc, 2020; 70(5): 118-123.

12. SIMPSON N, et al. Don't forget shared decision-making in the COVID-19 crisis. Internal Medicine Journal, 2020; 50(1): 761-763.

13. TURALE S, et al. Challenging times: ethics, nursing and the COVID-19 pandemic. International Nursing Review, 2020; 1(1): 164-167.

14. WANG H, et al. Contingency management strategies of the Nursing Department in centralized rescue of patients with coronavirus disease 2019. International Journal of Nursing Sciences, 2020; 7(1): 139-142.

15. ZHANG Y, et al. The Psychological Change Process of Frontline Nurses Caring for Patients with COVID-19 during Its Outbreak. Issues in mental health nursing, 2020; 41(6): 525-530. 